\title{
Altered gene expression in human placenta after suspected preterm labour
}

Oros D, ${ }^{a, b}$ Strunk M, ${ }^{c}$ Breton P, ${ }^{a}$ Paules C, ${ }^{a}$ Benito R, ${ }^{d}$ Moreno E, ${ }^{a}$ Garcés M, ${ }^{a}$ Godino J,

e Schoorlemmer Jf, g

a Aragon Institute for Health Research (IIS Aragón), Obstetrics Department, Hospital Clínico Universitario Zaragoza.

${ }^{b}$ Red de Salud Materno Infantil y del Desarrollo (SAMID), RETICS, Instituto de Salud Carlos III (ISCIII), Subdirección General de Evaluación y Fomento de la Investigación and Fondo Europeo de Desarrollo Regional (FEDER)

${ }^{\mathrm{C}}$ Instituto Aragonés de Ciencias de la Salud (IACS), Sequencing and Functional Genomics, Aragon Biomedical Research Center (CIBA).

${ }^{d}$ Aragon Institute for Health Research (IIS Aragón), Microbiology Department, Hospital Clínico Universitario Zaragoza.

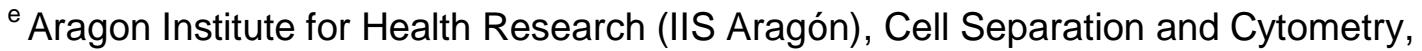
Aragon Biomedical Research Center (CIBA).

${ }^{f}$ Instituto Aragonés de Ciencias de la Salud (IACS) and Aragon Institute for Health Research (IIS Aragón), Pluripotency in Embryonic Stem Cells, Aragon Biomedical Research Center.

${ }^{g}$ ARAID Foundation, Zaragoza, Spain.

\section{Corresponding author:}

Daniel Oros

Hospital Clínico Universitario Lozano Blesa

C/ San Juan Bosco nำ15

50009 Zaragoza, SPAIN

Phone: 0034-976756700-162214

dorosl@salud.aragon.es 


\section{Abstract}

Introduction: Suspected preterm labour occurs in around 9\% of pregnancies. However, almost two-thirds of women admitted for threatened preterm labour ultimately deliver at term and are considered risk-free for fetal development.

Methods: We examined placental and umbilical cord blood samples from preterm or term deliveries after threatened preterm labour as well as term deliveries without threatened preterm labour. We quantitatively analysed the mRNA expression of inflammatory markers (IL6, IFNy, and TNFa) and modulators of angiogenesis (FGF2, PGF, VEGFA, VEGFB, and VEGFR1).

Results: A total of 132 deliveries were analysed. Placental samples from preterm and term deliveries after suspected preterm labour exhibited significantly increased expression of TNFa and IL6 and decreased expression of IFNy. Suspected preterm labour was also associated with altered expression of angiogenic factors, although not all differences reached statistical significance.

Discussion: We found gene expression patterns indicative of inflammation in human placentas after suspected preterm labour regardless of whether the deliveries occurred preterm or at term. Similarly, a trend towards altered expression of angiogeneic factors was not limited to preterm birth. These findings suggest that the biological mechanisms underlying threatened preterm labour affect pregnancies independently of gestational age at birth.

\section{Keywords}

Suspected preterm labour, angiogenesis, sterile inflammation, fetal development, placenta 


\section{Highlights}

- False preterm labour is considered to pose no risks to fetal development.

- Suspected preterm labour induces inflammatory gene expression in human placentas.

- Suspected preterm labour alters angiogenic gene expression in human placentas.

- Biological mechanisms of suspected preterm labour affect term-born pregnancies.

\section{Funding}

This work was supported by the Instituto Carlos III (Government of Spain (PI10/301) and the Department of Innovation, Research and University, Government of Aragón (B85-2014). 


\section{Introduction}

Suspected preterm labour occurs in approximately $9 \%$ of all pregnancies. ${ }^{1}$ However, almost two-thirds of women admitted for suspected preterm labour do not deliver prematurely. ${ }^{2}$ Women who deliver at term after suspected preterm labour are considered to have had an episode of "false preterm labour" that poses no risks to normal fetal development. ${ }^{3}$ However, previous reports suggest that at-term infants whose mothers experienced an episode of suspected preterm labour could be at increased risk for fetal growth restriction. ${ }^{4,5,6,7,8}$ Randomized clinical trials assessing the effect of tocolysis suggest that after suspected preterm labour, early childhood cognitive outcomes are similar between at-term and late-preterm infants. ${ }^{9}$ In line with these results, we recently reported an increased risk of suboptimal neurodevelopment in term-born 2-year-old children after an episode of suspected preterm labour. ${ }^{10}$ Hence, in some cases, symptoms of threatened preterm labour may result from a pathological insult whose nature or severity is not sufficient to induce irreversible spontaneous preterm delivery but that could alter the normal course of pregnancy because the fetus is subjected to an adverse intrauterine environment until delivery. $4^{11}$

Preterm birth is the final common result of a variety of aetiologies with very different biological mechanisms, ${ }^{12}$ some of which are related to poor neonatal outcomes. ${ }^{13,14}$ Previous efforts to prevent preterm birth have been hampered by a poor understanding of the underlying pathophysiology, inadequate diagnostic tools, and generally ineffective therapies. ${ }^{13}$ Nevertheless, clinical, epidemiological, and experimental studies indicate that acute and chronic inflammatory conditions in the placenta play a critical role in the pathogenesis of preterm birth. ${ }^{15,16}$ Failed invasion by extravillous trophoblast cells leads to placental dysfunction, which results in adverse obstetric outcomes including pre-eclampsia, fetal growth restriction, and spontaneous preterm delivery. Various endothelial cell-derived angiogenic and antiangiogenic factors are important for the invasion process to proceed normally. These include vascular endothelial growth factor (VEGF), its receptor fms-like tyrosine kinase-1 (FLT1), soluble FLT1 (sFLT1), placental growth factor (PGF), and fibroblast growth factor 2 (FGF2). ${ }^{17}$

To determine how inflammatory and angiogenic pathways are affected by suspected preterm labour, we examined the expression patterns of genes with known inflammatory and angiogenic functions in samples of umbilical cord blood and placenta from preterm and term deliveries after suspected preterm labour. 


\section{Methods}

Study population

We conducted a prospective cohort study of preterm (26-36 weeks) or term ( $\geq 37$ weeks) delivery pregnancies after suspected preterm labour between September 2011 and May 2013 at the Hospital Clínico Universitario of Zaragoza, a tertiary university center. Suspected preterm labour was defined as the presence of regular and painful uterine contractions registered by cardiotocography and ultrasound cervical length $<25$ $\mathrm{mm}$ in the presence of intact membranes at gestational age of $24+0$ to $36+6$ weeks. ${ }^{18}$ These groups were compared with a group of term delivery singleton pregnancies $(\geq 37$ weeks) without suspected preterm labour that were randomly sampled from our general obstetric population during the same time period. Last menstrual period was dated according to first-trimester crown-rump length. ${ }^{19}$ Pregnancies involving congenital malformations, chromosomopathies, infections, and multiple gestations were excluded. The local ethics committee approved the study protocol (CEICA 14/2010), and parents provided written informed consent.

All pregnancies were managed by a staff obstetrician. Tocolysis with atosiban (Tractocile, Ferring Pharmaceuticals, Madrid, Spain), intramuscular betamethasone $(2 \times 12 \mathrm{mg} / 24 \mathrm{~h})$, and magnesium sulphate was administered in some cases according to international clinical standards. ${ }^{20}$ Maternal sociodemographic characteristics and clinical data were recorded in the hospital database at study inclusion. Based on the results of previous studies, ${ }^{21}$ the number of subjects required for detecting a $>10 \%$ increase in markers of trophoblast inflammation assuming an alpha error of $5 \%$ and beta error of $20 \%$ was 110 .

\section{Placental and umbilical cord blood samples}

Samples of the placenta and umbilical cord blood were collected immediately after delivery. We identified sites at the placental periphery of four lobules that were free of visible infarction, calcification, haematoma or damage, and four tissue samples (1-2 $\mathrm{mm}$ ) were randomly removed from the maternal surface (basal plate). Tissue samples were submerged in RNA Stabilization Solution (RNAlater®, Fisher Scientific $®$ ), kept at $4^{\circ} \mathrm{C}$, and stored at $-80^{\circ} \mathrm{C}$ as suggested by the manufacturer.

Tissue homogenisation, RNA extraction, and mRNA expression analysis

Tissue stored at $-80^{\circ} \mathrm{C}$ in RNAlater ${ }^{\circledR}$ was thawed on ice. Small pieces (200-400 mg) were cut from each specimen using dissection scissors and mixed on ice with $1 \mathrm{ml}$ icecold TRIzol ${ }^{\mathrm{TM}}$, and then 1.0-mm Zirconia beads (Biospec Products) were added. 
Tissue was disrupted on a Mini Beadbeater (Biospec Products) for $4 \mathrm{~min}$ at room temperature. Cell debris and other particulate matter was removed by centrifugation $(3000 \mathrm{~g})$ at $4^{\circ} \mathrm{C}$. The resulting homogenate was frozen at $-80^{\circ} \mathrm{C}$ until further use. RNA was subsequently extracted using an in-house method ${ }^{22}$ based on standard TRIzol ${ }^{\mathrm{TM}}$ purification protocols (TRIzol®, Thermo Fischer Scientific) adapted from original protocols based on guanidinium thiocyanate. ${ }^{23}$ After DNase I treatment as previously described, ${ }^{22}$ RNA was resuspended, its concentration was measured using Nanodrop, and RNA was frozen at $-80^{\circ} \mathrm{C}$ until further use.

Reverse transcription $(R T)$ and quantitative polymerase chain reaction ( $q P C R$ )

Total RNA was obtained from 104 high-quality samples, as clinical circumstances precluded taking samples from 11 patients, and 18 other samples were excluded due to inconsistencies in clinical records $(n=8)$ or inappropriate storage $(n=10)$. Only samples with RIN values $>3.3$ were included in the study, although restricting the analysis to samples with RIN values $>6.0$ did not change the outcome (data not shown). RNAs were retrotranscribed using the High-Capacity RNA-to-cDNA ${ }^{\text {TM }}$ Kit (4387406, Applied Biosystems) at $20 \mathrm{ng} \mathrm{RNA} / \mu$ l reaction. Subsequent $\mathrm{qPCR}$ reactions were carried out using TaqMan® Gene Expression Master Mix (4370074, Applied Biosystems) with $5 \mathrm{ng}$ cDNA per reaction, oligos at $900 \mathrm{nM}$, and TaqMan probes at $250 \mathrm{nM}$ in $10 \mu \mathrm{l}$ reactions. All reactions were carried out in triplicate on a AB7900 HT apparatus (Applied Biosystems) using the following cycling protocol: 2 min at 50ㄷ, 10 $\min$ at $95^{\circ} \mathrm{C}$ and 40 cycles of $15 \mathrm{~s}$ at $95^{\circ} \mathrm{C}$ and $1 \mathrm{~min}$ at $60^{\circ} \mathrm{C}$. RT and qPCR assays were carried out by a commercial provider (Parque Científico de Madrid; www.fpcm.es). TaqMan ${ }^{\circledR}$ assays (Life Technologies) used to analyse the mRNA expression of inflammatory markers (interleukin 6 (IL6), interferon gamma (IFNY), and tumour necrosis factor alpha (TNFa)) and modulators of angiogenesis (FGF2, PGF, VEGFA, VEGFB, and VEGFR1). Data were normalised using GeNorm (URL); no significant differences were observed using either 18S rRNA or GAPDH as a reference gene. Expression suite (ThermoFisher Scientific) was used to calculate $\Delta \mathrm{Ct}$ values. Data were further recalculated as $\Delta \Delta \mathrm{Ct}$ with respect to the mean/median $\Delta \mathrm{Ct}$ value of control samples.

\section{Protein markers in serum}

Umbilical artery cord blood samples were obtained in 10-ml anti-coagulation tubes (EDTA/citrate), coagulated at room temperature, and centrifuged for $15 \mathrm{~min}$ at $1000 \mathrm{~g}$. After removal of 14 samples due to insufficient quality, we analysed 118 cord blood samples. Serum aliquots were stored at $-80^{\circ} \mathrm{C}$. We used the Magnetic Luminex 
screening assay from R\&D Systems to analyse protein levels for inflammatory markers and modulators of angiogenesis (RYD-LXSAHM-06). Duplicate assays were performed on $25 \mu \mathrm{l}$ of plasma according to the manufacturer's recommendations. Fluorescence measures were acquired using the Luminex200 platform (Luminex Corporation). A standard curve was generated by serially diluting reconstituted standards. Data were collected and analysed with Luminex xPONENT 3.1 software (Luminex Corporation). A five-parameter regression formula was used to calculate sample concentration (i.e., the mean value of the measurements) from the standard curve.

\section{Statistical analysis}

Normal distributions were assessed using Kolmogorov-Smirnov tests. Chi-square tests and analysis of variance (ANOVA) or Kruskal Wallis tests were used to analyse categorical and continuous variables, respectively. Spearman correlation coefficients ( $\rho$ ) were calculated, and $p$-values were based on the t distribution. Data are presented as mean \pm standard deviation (SD), median (interquartile range), or number of subjects (\%). Two-sided $p$-values $<0.05$ were considered statistically significant. Statistical analyses were performed using SPSS software (v. 20, SPSS Inc., Chicago, IL, USA). 


\section{Results}

A total of 140 pregnant women who satisfied the inclusion criteria were invited to participate in this study. As eight women declined, clinical samples were obtained from 132 women. Of these, 80 were admitted for threatened preterm labour. Preterm delivery occurred in 52 women (65\%), whereas the other 28 women delivered at term (35\%). A randomly selected group of 52 women who delivered at term without previous hospital admission were also included.

Maternal sociodemographic characteristics and perinatal data are shown in Table 1. There were no significant differences among groups in the sex of the infants or maternal age. More than two-thirds of preterm infants were delivered late preterm. Preterm infants had significantly lower birth weights and earlier gestational ages at delivery and were significantly more likely to be admitted to the neonatal care unit than term-born infants. Placental weights were significantly lower in the suspected preterm labour groups than in the term delivery control group. It is important to note that women in both suspected preterm labour groups had significantly greater rates of preterm birth in previous pregnancies.

We analysed protein levels of inflammatory markers and modulators of angiogenesis in umbilical cord blood samples from 118 women using composite chemiluminescence assays. Median values are shown in Table 2. No significant differences among groups were observed for IFNy, VEGF, FGF2, or IL6. Preterm delivery and term delivery after suspected preterm labour groups showed similar increases in TNFa expression compared with the term delivery control group. PGF expression was also increased after suspected preterm labour, with the percentage of subjects with PGF levels $>1.5$ multiples of the median (MoMs) in the term delivery control, term delivery after suspected preterm labour, and preterm delivery groups being $12.2,27.3$, and $42.2 \%$ $(p=0.004)$, respectively. There were significant positive correlations between the presence of suspected preterm labour and levels of TNFa $(0.265, p=0.004)$ and PGF $(0.375, p=0.001)$.

We also analysed mRNA expression of inflammatory markers and modulators of angiogenesis in 104 high-quality placental samples using RT and qPCR. Figure 1 shows values calculated for each gene for the suspected preterm labour groups relative to the term delivery control group. After suspected preterm labour, both the preterm delivery and term delivery groups showed increased expression of TNFa, IL6, and PGF and decreased expression of IFNY and VEGFR1. However, only the term delivery after suspected preterm labour group showed markedly decreased VEGFA 
expression, whereas only the preterm delivery group showed a slight decrease in VEGFB expression. FGF2 expression was similar across the three groups.

Statistical analysis showed significant differences among the three groups in VEGFB, TNFa, and IL6 mRNA expression in placental samples (Supplementary Table 1). To further investigate differences between groups, we performed pairwise comparisons (Figure 2). IL6 and TNFa mRNA expression were similarly increased in preterm delivery and term delivery after suspected preterm labour groups compared with the term delivery control group. However, the expression of VEGFB and VEGFR1 tended to be lower in the preterm delivery and term delivery after threatened preterm labour groups compared with the control group. A non-significant increase in PGF expression was also found in both threatened preterm labour groups.

Inflammation has previously been identified as a risk factor for preterm delivery. ${ }^{12,13,14}$ Therefore, we compared subjects with and without placental inflammation using the presence of both IL6 and TNFa mRNA expression >1.5 MoMs as a strict cut-off. Inflammation was present at similar frequencies in the preterm delivery and term delivery after suspected preterm labour groups (14.6\% vs. $13.6 \% ; p=0.946$ ). However, the presence of inflammation was significantly more frequent in both suspected preterm labour groups compared with the term delivery control group (14.2\% vs. $2.4 \%$; $p=0.045)$, (Figure $3 a$ ) with a positive likelihood ratio of 1.57 (95\% confidence interval, 1.20-2.05). We also found that the presence of suspected preterm labour correlated with increased IL6 $(0.287 ; p=0.003)$ and TNFa $(0.216 ; p=0.028)$ expression and decreased VEGFB expression $(-0.244 ; p=0.013)$, and the presence of inflammation was correlated with increased FGF2 expression $(0.377 ; p=0.002)$.

Re-evaluation of mRNA expression levels of angiogenic factors in placental samples indicated that inflammation was associated with significantly increased FGF2 expression (Figure 3). Therefore, we separated subjects with and without inflammation within both suspected preterm labour groups (Supplementary Table 2). 


\section{Discussion}

Our results suggest that similar biological mechanisms affect pregnancies after suspected preterm labour regardless of the final gestational age at birth. Specifically, we found the presence of gene expression patterns indicative of inflammation in human placentas delivered preterm and at term after suspected preterm labour.

Intra-amniotic inflammation/infection is the only mechanism with persuasive evidence of causality for spontaneous preterm delivery. ${ }^{24}$ Our results are consistent with those of previous studies linking increased levels of pro-inflammatory cytokines, placental pathology, and preterm delivery. ${ }^{11,12,13} \mathrm{Kim}$ et $a l,{ }^{25}$ found the presence of intraamniotic inflammation in the $12.1 \%$ of patients with an increased frequency of premature contractions without cervical changes. These results are in line with our study, as we report placental inflammation in $14.6 \%$ of the preterm delivery and $13.6 \%$ of the term delivery after suspected preterm labour patients. To avoid potential bias related to intra-amniotic inflammation, we excluded patients with preterm rupture of membranes at admission or who presented with clinical chorioamnionitis. Thus, we suggest that subclinical or sterile inflammation may be a contributing factor to preterm labour. We also found positive correlations between suspected preterm labour and both IL6 and TNFa gene expression, whereas previous studies of cytokine levels associated with preterm labour have largely examined single proteins independently. Our finding is compatible with that of a previous study showing that women with preterm labour and sterile intra-amniotic inflammation have more coordinated amniotic fluid inflammatoryrelated proteins than those without intra-amniotic inflammation. ${ }^{26}$

Reduced levels of VEGFA and PGF mRNA were previously observed in placentas from late preterm deliveries. ${ }^{27}$ We found decreased levels of placental VEGFB mRNA not only in the preterm delivery group but also in the term delivery after suspected preterm labour group, which was consistent with a trend toward decreased expression of VEGFA and VEGFR1. Whether the role of the VEGF pathway in threatened preterm labour is related to angiogenesis ${ }^{28}$ or an indirect reduction in circulating progesterone levels and subsequent onset of labour and parturition ${ }^{29}$ is an unresolved question at present.

It has been hypothesized that the symptoms of threatened preterm labour result from a pathological insult whose nature and/or severity is not sufficient to induce irreversible spontaneous preterm birth but is sufficient to disturb pregnancy ${ }^{11}$. A growing body of evidence suggests that term-born fetuses after threatened preterm labour have an increased risk of low birthweight ${ }^{4,5,6,7,8}$ and adverse perinatal outcomes, such as higher 
rates of instrumental deliveries, non-reassuring fetal heart rate tracings, prolonged third stage of labour, and increased rate of post-partum maternal anaemia. ${ }^{30}$ We recently found that children born at term after threatened preterm labour have an increased risk of suboptimal neurodevelopment at 2 years of $\mathrm{age}^{10}$, which is in line with other reports ${ }^{11}$. Intrauterine inflammation to a level insufficient to cause parturition may be sufficient to induce fetal injury, even without a maternal immune response. ${ }^{31}$ Here, we observed gene expression patterns indicative of inflammation in human placentas after suspected preterm labour regardless of whether the deliveries occurred preterm or at term. To the best of our knowledge, this is the first reported evidence of a similarity between these two groups. So far, concerns regarding suspected preterm labour have focused on preventing preterm birth, but suspected preterm labour itself might be a risk factor for prenatal and postnatal adverse outcomes, suggesting the need for more surveillance.

The main strength of our study is that no previous studies have examined the effect of suspected preterm labour on placental inflammation and angiogenic pathways. However, our study also has some limitations. First, our study design did not allow us to examine whether the treatment applied during a suspected preterm labour episode could influence placental gene expression. Experimental and observational studies in necropsies on preterm babies showed that glucocorticosteroids induce apoptosis in the hippocampal neurons in animals as well as human fetuses. ${ }^{32,33}$ Second, alterations in angiogenesis-related gene expression were found in both groups after suspected preterm labour, although many of these differences did not reach statistical significance. We plan to strengthen our conclusions in the future through a study with larger cohorts and determination of protein levels and enzyme activity. In addition, determining protein levels, enzymatic activities, and their localisation may enhance our understanding of the molecular processes underlying suspected preterm labour.

We found gene expression patterns indicative of inflammation in human placentas after suspected preterm labour regardless of whether delivery occurred preterm or at term. Alterations in angiogenesis-related gene expression were also found after suspected preterm labour, although not all differences reached statistical significance. These results suggest that similar biological mechanisms affect both preterm and term-born infants after suspected preterm labour. Further studies are needed to understand the possible implications of these findings for fetal development. 


\section{Author contributions}

Daniel Oros: I declare that I participated in the study protocol development, placental and cord blood samples collection and statistical analysis of the results, and that I have seen and approved the final version.

Mark Strunk: I declare that I participated in the study protocol development, in the placental sample analysis and in the statistical analysis of the results, and that I have seen and approved the final version.

Patricia Breton: I declare that I participated in the placental and cord blood samples collection, and that I have seen and approved the final versión.

Cristina Paules: I declare that I participated in the placental and cord blood samples collection, and that I have seen and approved the final versión.

Rafael Benito: I declare that I participated in the study protocol development, and in the placental and cord blood samples collection and that I have seen and approved the final version

Esther Moreno: I declare that I participated in the placental and cord blood samples collection, and that I have seen and approved the final versión.

Marta Garcés: I declare that I participated in the placental and cord blood samples collection, and that I have seen and approved the final versión.

Javier Godino: I declare that I participated in the study protocol development and placental and cord blood analysis, and that I have seen and approved the final version. Jon Schoorlemmer: I declare that I participated in the study protocol development, in the placental samples analysis and in the statistical analysis of the results, and that I have seen and approved the final version. 


\section{References}

1 Bacak SJ, Callaghan WM, Dietz PM, Crouse C. Pregnancy-associated hospitalizations in the United States, 1999-2000. Am J Obstet Gynecol. 2005;192(2):592-597.

${ }^{2}$ McPheeters ML, Miller WC, Hartmann KE, et al. The epidemiology of threatened preterm labor: a prospective cohort study. Am J Obstet Gynecol 2005;192:1325-9; discussion 139-30.

${ }^{3}$ Grover Cm, Posner S, Kupperman M, Washington EA. Term delivery after hospitalization for preterm labor: incidence and cost in California. Prim Care Update Ob Gyns 1998; 5: 178.

${ }^{4}$ Espinoza J, Kusanovic JP, Kim CJ, et al. An episode of preterm labor is a risk factor for the birth of a small-for-gestational-age neonate. Am $J$ Obs Gynecol. 2007;196(6):574 e1-e5; discussion 574 e5-e6.

${ }^{5}$ Campbell MK, Cartier S, Xie B, Kouniakis G, Huang W, Han V. De- terminants of small for gestational age birth at term. Paediatr Perinat Epidemiol 2012;26:525-33.

${ }^{6}$ Zoabi L, Weintraub AY, Novak L, et al. Do patients who deliver at term after being hospitalized for preterm contractions have an increased risk for obstetrical complications? Arch Gynecol Obstet 2013;288:537-42.

${ }^{7}$ Lampl M, Gotsch F, Kusanovic JP, et al. Downward percentile crossing as an indicator of an adverse prenatal environment. Ann Hum Biol 2008;35:462-74.

${ }^{8}$ Lampl M, Kusanovic JP, Erez O, et al. Early rapid growth, early birth: accelerated fetal growth and spontaneous late preterm birth. Am J Hum Biol 2009;21:141-50.

${ }^{9}$ Hughes A, Greisen G, Arce J-C, Thornton S. Late preterm birth is associated with short-term morbidity but not with adverse neurodevelopmental and physical outcomes at 1 year. Acta Obstet Gynecol Scand. 2014;93(1):109-112.

${ }^{10}$ Paules C, Pueyo V, Martí E, Vilchez S, Burd I, Calvo P, Oros D. Threatened preterm labor is a risk factor for impaired cognitive development in early childhood. Am J Obstet Gynecol. 2017 Feb;216(2):157.e1-157.e7.

${ }^{11}$ Romero R, Erez O, Maymon E, Pacora P. Is an episode of suspected preterm labor that subsequently leads to a term delivery benign?. Am J Obstet Gynecol. 2017 Feb;216(2):89-94.

${ }^{12}$ Goldenberg RL, Gravett MG, lams J, et al. The preterm birth syndrome: issues to consider in creating a classification system. Am J Obstet Gynecol. 2012;206(2):113118.

${ }^{13}$ Romero R, Espinoza J, Kusanovic J, et al. The preterm parturition syndrome. BJOG. 2006;113:17-42.

${ }^{14}$ Brown H, Speechley K, Macnab J, Natale R, Campbell M. Biological determinants of spontaneous late preterm and early term birth: a retrospective cohort study. BJOG. 2014:1-9.

${ }_{15}$ Romero R, Espinoza J, Goncalves LF, Kusanovic JP, Friel LA, Nien JK. Inflammation in preterm and term labour and delivery. Semin Fetal Neonat Med 2006;11:317-26.

${ }^{16}$ Salafia C, Popek E, Glob. libr. women's med., (ISSN: 1756-2228) 2008; September 11, 2015.

17 Charnock-Jones DS1, Kaufmann P, Mayhew TM.Placenta. Aspects of human fetoplacental vasculogenesis and angiogenesis. I. Molecular regulation. 2004 Feb-Mar; $25(2-3): 103-13$.

${ }^{18}$ Instituto Nacional Materno Perinatal. Amenaza de Parto Pretérmino. Guias Pract Clin y Procedimientos en Obstet y Perinatol. 2010;(2012):97-102.

${ }_{19}$ Robinson HP, Fleming JEE. A critical evaluation of sonar "crown-rump length" measurements. Br J Obstet Gynaecol. 1975;82(9):702-710.

${ }^{20}$ ACOG practice bulletin no. 127: Management of preterm labor. Obstet Gynecol. 2012 Jun;119(6):1308-17. 
${ }^{21}$ Park HS, Romero R, Lee SM, Park CW, Jun JK, Yoon BH. Histologic chorioamnionitis is more common after spontaneous labor than after induced labor at term. Placenta. 2010 Sep;31(9):792-5.

${ }_{22}$ Pérez-Palacios R, Macías-Redondo S, Climent M, Contreras-Moreira B, Muniesa P, Schoorlemmer J. In Vivo Chromatin Targets of the Transcription Factor Yin Yang 2 in Trophoblast Stem Cells. PLoS One. 2016 May 18;11(5):e0154268.

${ }^{23}$ Chomczynski P, Sacchi N. Single-step method of RNA isolation by acid guanidinium thiocyanate-phenol-chloroform extraction. Anal Biochem. 1987 Apr;162(1):156-9.

${ }^{24}$ Kim CJ, Romero R, Chaemsaithong P, Kim JS. Chronic inflammation of the placenta: definition, classification, pathogenesis, and clinical significance. Am J Obstet Gynecol. 2015 Oct; 213(4 Suppl):S53-69.

${ }^{25} \mathrm{Kim}$ SM, Romero R, Lee J, et al. The frequency and clinical significance of intraamniotic inflammation in women with preterm uterine contractility but without cervical change: do the diagnostic criteria for preterm labor need to be changed? J Matern Fetal Neonat Med 2012;25:1212-21.

${ }^{26}$ Romero $\mathrm{R}^{1}$, Grivel $\mathrm{JC}^{2}$, Tarca $\mathrm{AL}^{3}$, Chaemsaithong $\mathrm{P}^{3}, \mathrm{Xu} \mathrm{Z}^{3}$, Fitzgerald $\mathrm{W}^{4}$, Hassan $\mathrm{SS}^{3}$, Chaiworapongsa $\mathrm{T}^{3}$, Margolis $\mathrm{L}^{4}$. Evidence of perturbations of the cytokine network in preterm labor. Am J Obstet Gynecol. 2015 Dec; 213(6):836.e1-836.e18.

${ }^{27}$ Andraweera PH, Dekker GA, Laurence JA, Roberts CT. Placental expression of VEGF family mRNA in adverse pregnancy outcomes. Placenta. 2012 Jun; 33(6):46772.

${ }^{28}$ Andraweera PH, Dekker GA, Roberts CT. The vascular endothelial growth factor family in adverse pregnancy outcomes. Hum Reprod Update. 2012 Jul;18(4):436-57.

${ }^{29}$ Langmia IM, Apalasamy YD, Omar SZ, Mohamed Z. Association of VEGFA gene polymorphisms and VEGFA plasma levels with spontaneous preterm birth. Pharmacogenet Genomics. 2015 Apr;25(4):199-204.

${ }^{30}$ Ganer Herman $\mathrm{H}^{1}$, Miremberg $\mathrm{H}^{2}$, Dekalo $\mathrm{A}^{3}$, Barda $\mathrm{G}^{4}$, Bar $\mathrm{J}^{5}$, Kovo $\mathrm{M}^{6}$. Preterm uterine contractions ultimately delivered at term: safe but not out of danger. Eur $\mathrm{J}$ Obstet Gynecol Reprod Biol. 2016 Apr;199:1-4.

${ }^{31}$ Bastek JA, Weber AL, McShea MA, Ryan ME, Elovitz MA. Prenatal inflammation is associated with adverse neonatal outcomes. Am J Obstet Gynecol. 2014;210(5):450.e1-e10.

${ }^{32}$ Noorlander CW, Tijsseling D, Hessel EV, et al. Antenatal glucocorti- coid treatment affects hippocampal development in mice. PloS One 2014;9:e85671.

${ }^{33}$ Tijsseling D, Wijnberger LD, Derks JB, et al. Effects of antenatal glucocorticoid therapy on hippocampal histology of preterm infants. PloS One 2012;7:e33369. 


\section{Figure legends}

Figure 1. mRNA expression of inflammatory markers and modulators of angiogenesis in placental samples from preterm and term deliveries after threatened preterm labour relative to term control deliveries. Data are shown as mean $\pm S D$.

Figure 2. mRNA expression of inflammatory markers and modulators of angiogenesis in placental samples. Data are shown as median (interquartile range). Data were analysed using Kruskal Wallis tests. TDSPL: term delivery after suspected preterm labour.

Figure 3. (a) Percentage of cases with inflammation (both threatened preterm labour groups combined). Inflammation was defined by both IL6 and TNF $\alpha$ mRNA expression $>1.5$ MoMs. (b-f). mRNA expression of inflammatory markers and modulators of angiogenesis in placental samples depending on the state of inflammation. Data are shown as median (interquartile range). 
Table 1. Maternal sociodemographic characteristics and perinatal data.

\begin{tabular}{|c|c|c|c|c|}
\hline & $\begin{array}{l}\text { Preterm } \\
\text { delivery } \\
(n=52)\end{array}$ & $\begin{array}{c}\text { Term delivery } \\
\text { after suspected } \\
\text { preterm labour } \\
(\mathrm{n}=28) \\
\end{array}$ & $\begin{array}{c}\text { Term delivery } \\
\text { control } \\
(n=52)\end{array}$ & $p$ \\
\hline Maternal age, mean (SD) & $29.7(5.8)$ & $30.2(6.2)$ & $31.1(5.7)$ & 0.523 \\
\hline $\begin{array}{l}\text { Maternal body mass index, } \mathrm{kg} / \mathrm{m}^{2} \text {, } \\
\text { mean (SD) }\end{array}$ & $23.4(3.4)$ & $21.7(2.8)$ & $25.1(3.9)$ & 0.001 \\
\hline $\begin{array}{l}\text { Gravity, median (interquartile } \\
\text { range) }\end{array}$ & $1(3)$ & $1(3)$ & $0(6)$ & 0.649 \\
\hline $\begin{array}{l}\text { Parity, median (interquartile } \\
\text { range) }\end{array}$ & $0(3)$ & $0(2)$ & $0(1)$ & 0.073 \\
\hline Caucasian, n (\%) & $42(80.8)$ & $27(96.4)$ & $45(86.5)$ & 0.420 \\
\hline Smokers, n (\%) & $5(9.6)$ & $2(7.1)$ & $8(15.4)$ & 0.562 \\
\hline Preeclampsia, n (\%) & $1(1.9)$ & $2(7.1)$ & $0(0.0)$ & 0.124 \\
\hline Gestational diabetes, n (\%) & $1(1.9)$ & $2(7.1)$ & $3(5.8)$ & 0.487 \\
\hline Infant sex, male, n (\%) & $23(44.2)$ & $20(71.4)$ & $26(50.0)$ & 0.062 \\
\hline $\begin{array}{l}\text { Gestational age at birth, days, } \\
\text { mean (SD) }\end{array}$ & $243(16.2)$ & $272(9.1)$ & $278(7.1)$ & 0.001 \\
\hline Previous preterm delivery, n (\%) & $9(17.3)$ & $5(17.9)$ & $1(1.9)$ & 0.023 \\
\hline Birth weight, g, mean (SD) & $2300(522.2)$ & 3152 (351.9) & 3247 (347.0) & 0.001 \\
\hline Placental weight, g, mean (SD) & $456.63(149.9)$ & $536.63(130.9)$ & $606.15(90.2)$ & 0.001 \\
\hline Cesarean section, n (\%) & $5(9.6)$ & $6(21.4)$ & $12(23.1)$ & 0.160 \\
\hline Labour, n (\%) & $50(96.2)$ & $23(82.1)$ & $42(80.8)$ & 0.044 \\
\hline Cervical ripening ${ }^{*}, \mathrm{n}(\%)$ & $0(0.0)$ & $7(25.0)$ & $11(21.2)$ & 0.001 \\
\hline Epidural anesthesia, n (\%) & $40(76.9)$ & $25(89.3)$ & $48(94.1)$ & 0.035 \\
\hline Antibiotics in labour ${ }^{* *}, \mathrm{n}(\%)$ & $17(32.7)$ & $7(25.0)$ & $8(15.4)$ & 0.118 \\
\hline Tocolysis ${ }^{* * *}, \mathrm{n}(\%)$ & $46(88.4)$ & $24(85.7)$ & $0(0.0)$ & 0.009 \\
\hline Antenatal steroids, n (\%) & $21(40.4)$ & $28(100)$ & $0(0.0)$ & 0.001 \\
\hline $\begin{array}{l}\text { Maternal oxygen at delivery, } \mathrm{n} \\
(\%)\end{array}$ & $0(0.0)$ & $0(0.0)$ & $0(0.0)$ & 1 \\
\hline Magnesium sulphate, n (\%) & $6(11.5)$ & $0(0.0)$ & $0(0.0)$ & 0.008 \\
\hline Apgar at 5 minutes $<7, \mathrm{n}(\%)$ & $0(0.0)$ & $0(0.0)$ & $0(0.0)$ & 1 \\
\hline $\begin{array}{l}\text { Neonatal care unit admission, } \mathrm{n} \\
(\%)\end{array}$ & $30(56)$ & $3(11.1)$ & $4(8.3)$ & 0.001 \\
\hline Umbilical artery $\mathrm{pH}<7.10, \mathrm{n}(\%)$ & $0(0.0)$ & $0(0.0)$ & $3(5.8)$ & 0.207 \\
\hline
\end{tabular}

*prostaglandin E2; **ampicilin; ${ }^{* *}$ atosiban. Data were analysed using ANOVA (continuous variables) or Chi-square tests (categorical variables). 
Table 2. Protein concentrations $(\mathrm{pg} / \mathrm{ml}$ ) of inflammatory markers and modulators of angiogenesis in umbilical artery cord blood samples.

\begin{tabular}{lcccc}
\hline & $\begin{array}{c}\text { Preterm delivery } \\
(\mathbf{n}=47)\end{array}$ & $\begin{array}{c}\text { Term delivery after } \\
\text { suspected preterm labour } \\
(\mathbf{n}=\mathbf{2 2})\end{array}$ & $\begin{array}{c}\text { Term delivery } \\
\text { control } \\
(\mathbf{n}=49)\end{array}$ & $\boldsymbol{p}$ \\
\hline PGF & $1.29(1.59)$ & $0.8(1.01)$ & $0.64(0.74)$ & 0.001 \\
TNFa & $3.63(2.59)$ & $3.63(3.76)$ & $2.78(2.02)$ & 0.011 \\
IL6 & $3.70(13.48)$ & $2.05(5.78)$ & $1.82(4.13)$ & 0.107 \\
FGF2 & $5.70(68.35)$ & $0.00(36.47)$ & $0.00(41.28)$ & 0.188 \\
IFNy & $0.18(0.37)$ & $0.14(0.30)$ & $0.18(0.19)$ & 0.546 \\
VEGF & $48.65(82.93)$ & $48.65(140.55)$ & $42.30(156.23)$ & 0.746 \\
\hline
\end{tabular}

FGF2: fibroblast growth factor 2, IFNY: interferon gamma, PGF: placental growth factor, TNFa: tumour necrosis factor alpha, IL6: interleukin 6, VEGF: vascular endothelial growth factor. Data are shown as median (interquartile range). Data were analysed using Kruskal Wallis tests. 
Supplementary Table 1. mRNA expression of inflammatory markers and modulators of angiogenesis in placental samples.

\begin{tabular}{lcccc}
\hline & $\begin{array}{c}\text { Preterm } \\
\text { delivery } \\
(\mathbf{n}=\mathbf{4 1})\end{array}$ & $\begin{array}{c}\text { Term delivery after } \\
\text { threatened preterm labour } \\
(\mathbf{n = 2 2})\end{array}$ & $\begin{array}{c}\text { Term } \\
\text { delivery } \\
\text { control } \\
(\mathbf{n}=41)\end{array}$ & $\boldsymbol{p}$ \\
\hline VEGFB & $0.85(0.26)$ & $0.97(0.23)$ & $1.03(0.36)$ & 0.002 \\
IL6 & $1.28(0.74)$ & $1.24(0.74)$ & $0.93(0.76)$ & 0.014 \\
TNF $\alpha$ & $1.20(0.88)$ & $1.39(0.97)$ & $0.97(0.82)$ & 0.048 \\
PGF & $1.42(0.96)$ & $1.37(0.95)$ & $1.19(0.75)$ & 0.343 \\
FGF2 & $1.02(0.48)$ & $1.18(1.72)$ & $1.07(0.55)$ & 0.342 \\
VEGFA & $0.87(0.97)$ & $0.78(0.51)$ & $0.91(0.70)$ & 0.370 \\
VEGFR1 & $0.78(0.70)$ & $0.81(0.79)$ & $1.03(0.79)$ & 0.581 \\
INF $\gamma$ & $0.59(1.76)$ & $0.85(1.67)$ & $0.72(2.17)$ & 0.763 \\
\hline
\end{tabular}

Data are shown as median (interquartile range). Data were analysed using Kruskal Wallis tests. 
Supplementary Table 2. mRNA expression of modulators of angiogenesis in placental samples depending on the state of inflammation.

\begin{tabular}{lcccccc}
\hline & \multicolumn{2}{c}{ Preterm delivery } & \multicolumn{4}{c}{$\begin{array}{c}\text { Term delivery after suspected } \\
\text { preterm labour }\end{array}$} \\
\hline & $\begin{array}{c}\text { Inflammation } \\
(\mathbf{n}=6)\end{array}$ & $\begin{array}{c}\text { No } \\
\text { inflammation } \\
(\mathbf{n}=35)\end{array}$ & $\boldsymbol{p}$ & $\begin{array}{c}\text { Inflammation } \\
(\mathbf{n}=3)\end{array}$ & $\begin{array}{c}\text { No } \\
\text { inflammation } \\
(\mathbf{n}=19)\end{array}$ & $\boldsymbol{p}$ \\
\hline PGF & $0.76(1.41)$ & $1.45(0.96)$ & 0.110 & $1.51(1.32)$ & $1.37(0.93)$ & 0.651 \\
FGF2 & $1.85(1.48)$ & $0.99(0.40)$ & 0.018 & $1.07(0.55)$ & $1.14(0.40)$ & 0.087 \\
VEGFA & $1.71(3.42)$ & $0.87(0.54)$ & 0.171 & $1.11(0.66)$ & $0.75(0.47)$ & 0.718 \\
VEGFB & $0.79(0.44)$ & $0.85(0.26)$ & 0.438 & $1.18(0.10)$ & $0.96(0.19)$ & 0.408 \\
VEGFR1 & $0.61(0.96)$ & $0.80(0.76)$ & 0.376 & $0.71(0.39)$ & $0.85(2.07)$ & 0.523
\end{tabular}

Inflammation was defined by the presence of placental IL6 and TNFa mRNA expression >1.5 MoMs. Data are shown as median (interquartile range). Data were analysed using Kruskal Wallis tests. 
$1 \quad$ Figure 1

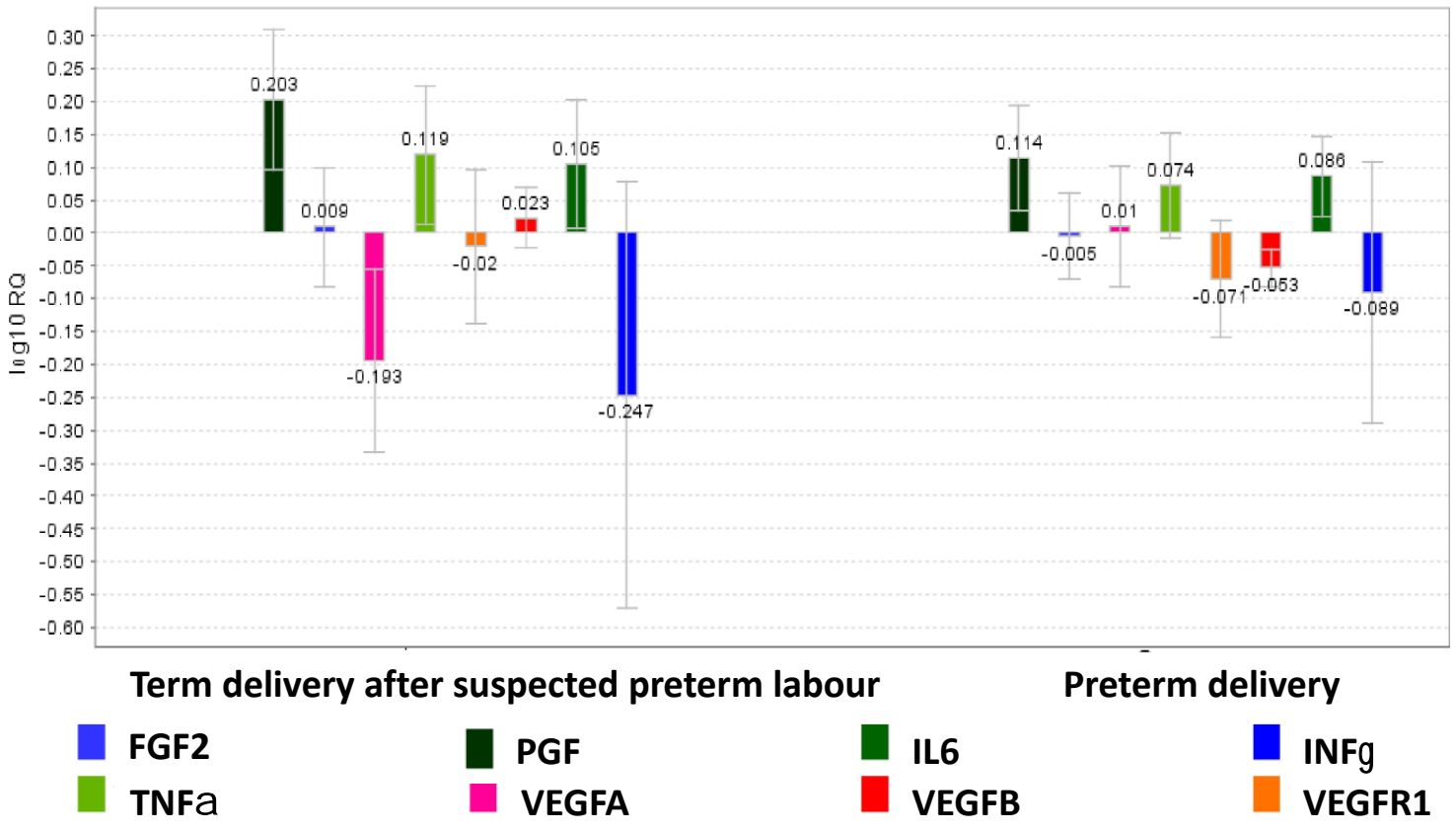


$1 \quad$ Figure 2
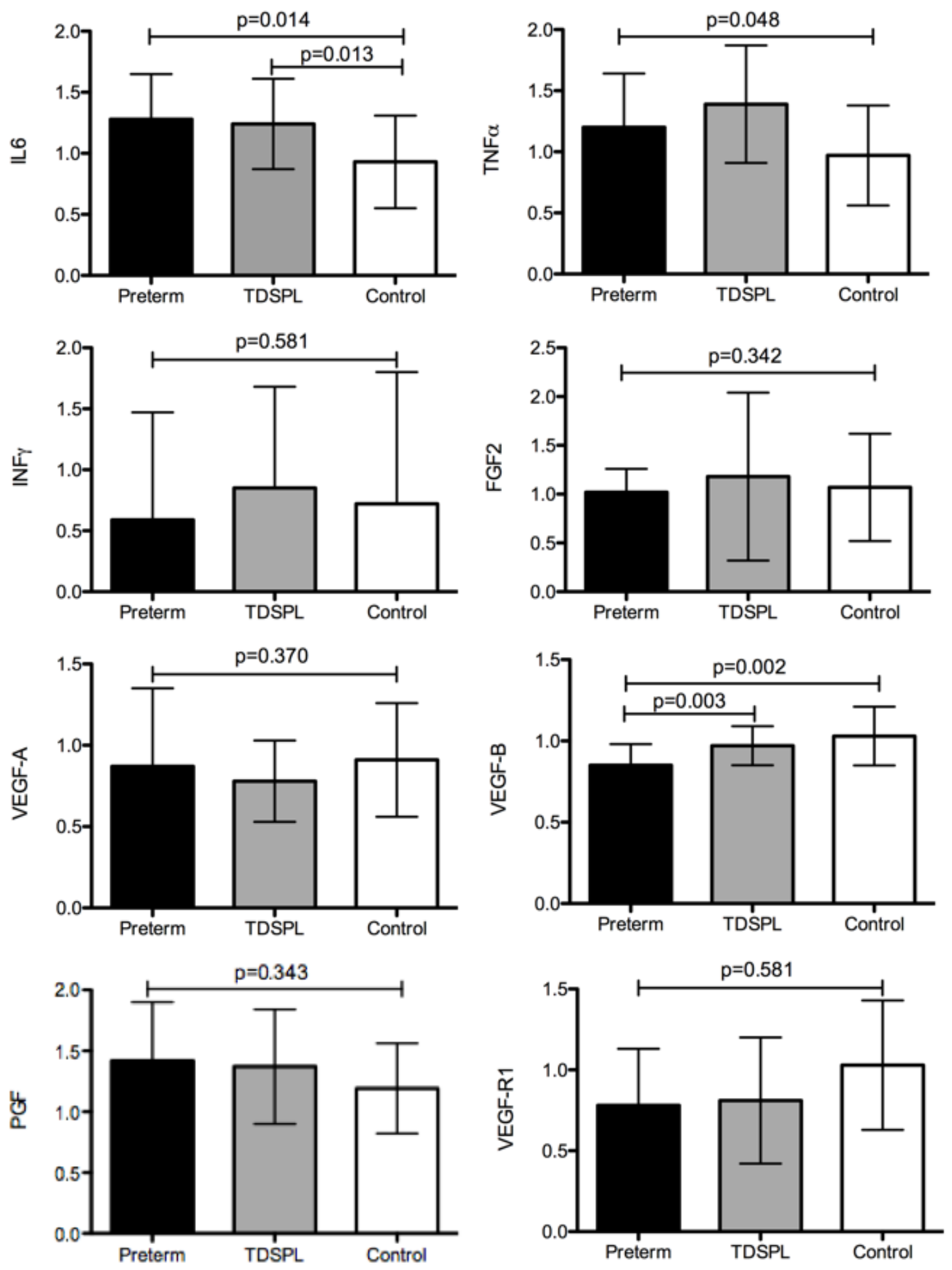
Figure 3
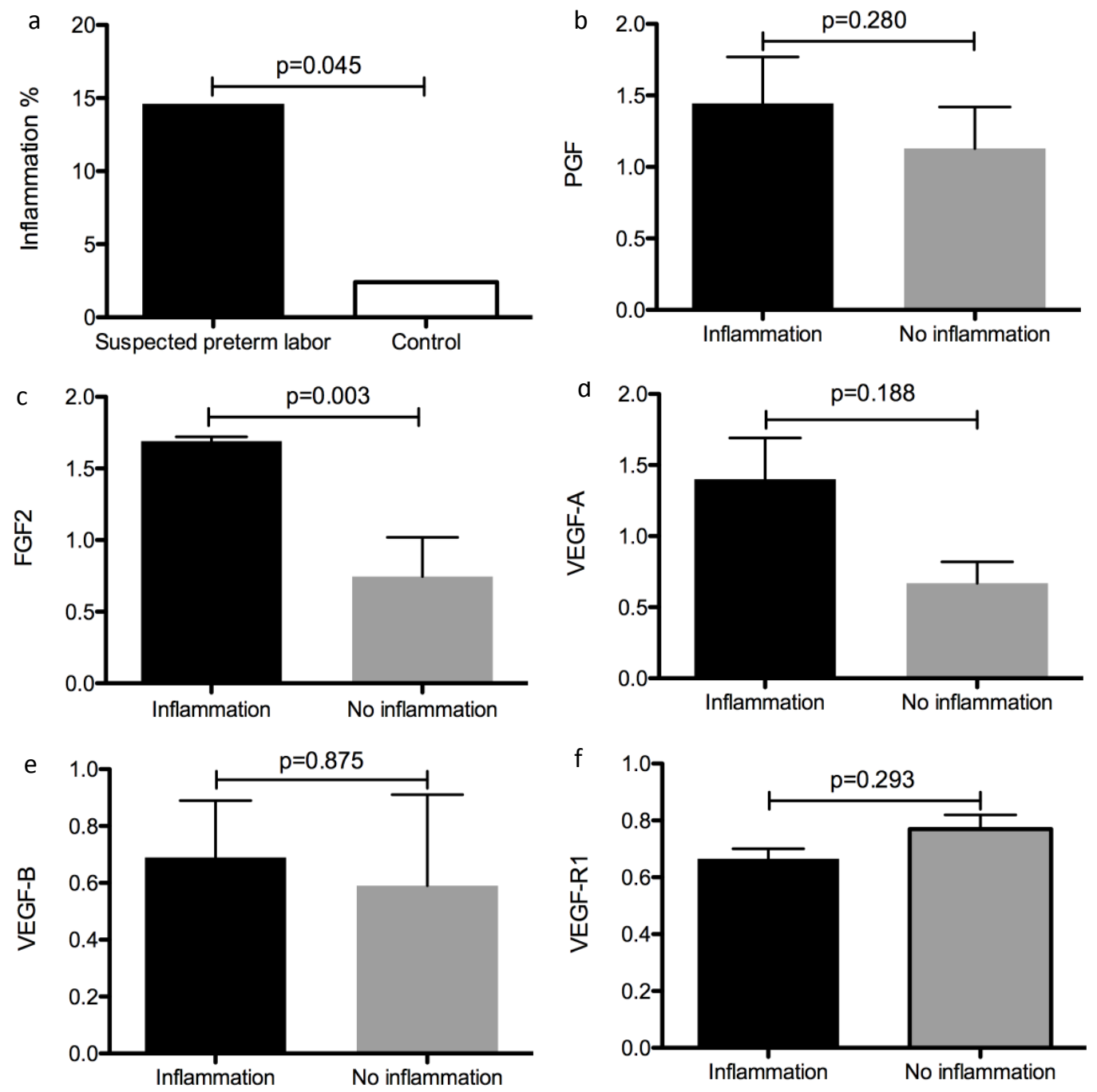